\title{
Constructive fire protection of steel corrugated beams of buildings and other structures
}

\author{
Nikolay Ilyin ${ }^{1}$, Denis Panfilov ${ }^{1, *}$, and Aleksey Lukin ${ }^{1}$ \\ ${ }^{1}$ Samara State Technical University, Institute of Architecture and Civil Engineering, 194, \\ Molodogvardeyskaya St., 443001, Samara, Russia
}

\begin{abstract}
The research introduces a methodology of establishing indicators of fire safety of a building in relation to a guaranteed duration of steel fire-proof corrugated beams resistance in conditions of standard fire tests. Indicators of fire safety are also established in the assessment of design limits of steel fire-proof corrugated beams during design process, construction or maintenance of the building as well as in reducing economic costs when testing steel structures for fire resisting property. The suggested methodology introduces the system of actions aimed to design constructive fire protection of steel corrugated beams of buildings. Technological effect is achieved by conducting firing tests of steel construction by non-destructive methods; the evaluation of fire resistance of fire-proof elements of corrugated beams (corrugated web, upper and lower shelves) is identified by the least fire-proof element of a welded Ibeam. In this methodology fire resistance duration of the constituent elements of a welded I-beam with account of its fire protection ability is described with an analytic function taken as variables. These variables are intensity strength of stresses and the degree of fire protection of a compound element.
\end{abstract}

\section{Introduction}

A steel beam with a flexible wall, in which a corrugated web works beyond the range of stability, is referred to new types of structures due to its efficient constructive form. A steel beam with corrugated web is characterized by augmented stability, and significant reduction of the wall thickness leads to considerable saving of steel used to make a beam.

However, the problem of resource saving for constructive fire resistance of these beams has not yet been solved $[1,4,5]$.

The researchers studied different methods of fire protection and fire resistance evaluation (GOST R 53309-2009) of effective steel beam structures in ASI SGTU, carried out thematic patent search, set the level of technological development, the scope and novelty of the research object, defined analogies (GOST 30247.1-94) and the prototype [1] of a new technical solution [2].

The need for assessment of fire resistance of steel fire-resistant corrugated beams occurs during reconstruction of buildings or structures (hereinafter referred to as

\footnotetext{
* Corresponding author: panda-w800i@yandex.ru
} 
'buildings'), strengthening their parts, bringing the actual fire-resistant steel beams in accordance with modern requirements of the Federal Law (Federal Law № 123-08): "Technical regulations of fire safety requirements (with 2012 amend.) during the examination and/or repair of steel constructions of the building after the fire".

\section{Materials and Methods}

The researchers conducted a test and found an analogue (prototype) action method of the evaluation of fire resistance of steel fire-proof corrugated beams of a building. The chosen method includes technical inspection, tool measurement of geometric characteristics of steel beams in bending; identifying conditions of bearing and mounting of beams, heating schemes for a cross-section; setting the type of fire-retardant material and a mark of steel beams, metal characteristics of resistance to bending and stretching; determining test load on the steel beam and a scheme for its application and intensity of strength stress in the metal at the dangerous section of a steel beam. The evaluation of fire resistance of steel fire-proof corrugated beam of a building is done according to Programme [3]. However, using a nomograph for evaluating fire resistance of a steel fire-proof corrugated beam of a building produces calculation results of low accuracy, and in some cases it is required to make an additional nomographic chart. In addition, indicators of reliability of steel beams according to the level of safety is not taken into account. Developing computer software for calculating the design limit of fire resistance of a corrugated beam is also rather challenging.

The suggested methodology makes possible to delete field fire tests of steel constructions in a building or in its part; reduce complexity of determining fire resistance of steel structures; expand technological capabilities of design evaluation of fire resistance of variously stressed steel corrugated beams of different sizes and the ability to compare the results with similar tests of other steel building structures; reduce economic costs of testing; simplify the conditions and shorten test-time of steel structures for fire resisting property; improve accuracy and test speed, if necessary; use the design parameters for evaluating fire resistance of steel thermo-protected corrugated beams and simplify a mathematical description of the resistance process of loaded steel structures; take into account real resource of fire-proof corrugated beam for fire resisting property by using a complex of single indicators of their qualities; increase accuracy calculating fire protection thickness and steel heating conditions of a corrugated beam in case of fire; clarify individual quality parameters of structures affecting their fire resistance [2].

\section{Results}

Evaluation of fire resistance of steel fire-proof corrugated beam of a building suggested in the author's methodology should be conducted without exposure to high temperatures of non-destructive testing but by using a complex of single indicators of the quality of steel structures. The peculiarity of the method lies in the fact that initially geometrical characteristics of the constituent elements of welded I-beams are revealed. These constituent elements include corrugated webs, the lower and upper shelves, as well as steel amplifier elements. The perimeter of a heating section of each constituent element of welded I-beams is calculated; intensity of strength stress in the cross section of the corrugated web and in the lower and upper shelves of a welded I-beam is found; the duration of fire resistance effects for every part of a welded I-beam without fire protection is determined; the depth of coverage according to the direction of checkpoint shift for finding the average temperature of the unevenly heated section of the shelf of a welded I- 
beam is calculated; indicators of conditions for checkpoints in the shelves and in corrugated webs of a welded I-beam with protective coating in conditions of a standard fire test are calculated; the degree of fire protection of compound elements of a welded I-beam is determined. Then, compound elements of a welded I-beam are considered to be parts of a truss frame with parallel flanges. After that, the duration of fire resistance of a corrugated web, bottom and top shelves of a welded I-beam (considering their fire protection) is calculated; the least stable element (according to its statical and heat-resistant characteristics) of a welded I-beam at the minimum duration of fire resistance effects of corrugated webs and bottom or top shelves of a welded I-beams with account of fire protection is pointed out,

The design limit of fire resistance $F_{u r}$, min, of a steel fire-proof corrugated beam according to its loss of bearing ability is determined by the duration of fire resistance effects of compound elements of a welded I-beam according to its statical and heat-resistant characteristics $r_{u s, \min }$, $\min$; that is

$$
F_{u r}=r_{u s, \text { min }} \text {. }
$$

In the cross-section of a welded h-beam shelf, intensity of strength stresses from test load in conditions of fire tests $J_{\sigma s}$ is calculated by the equation

$$
J_{\sigma s}=M_{\rho} /\left(W_{n} \square R_{y n}\right),
$$

where $M_{\rho}$ is the bending moment in a dangerous section of test load for fire resistance, $k N$ $m ; W_{n}$ is the resistance moment of cross-section shelf of a welded I-beam for its horizontal axis, $\mathrm{cm}^{3} ; R_{u n}$ - normative tensile strength and compression resistance for the point of steel yielding, Mpa [5; 6].

In the cross-section of a welded I-beam shelf, the intensity of strength stress is calculated while using the condition

$$
J_{\sigma s}=1 / n_{o},
$$

where $n_{o}$ is an integral factor of bearing capacity by fire resistance of a steel thermoprotected beam of a building.

In the cross-section of a corrugated web of a welded I-beam, the intensity of strength stresses is equal to

$$
J_{\sigma S, 3}=0,07 \pm 0,03
$$

Fire resistance duration of compound elements of a welded I-beam without its thermal protection capacity $r_{u s, i}$, min is determined by the analytical equation

$$
\left.r_{u s, i}=6 \square\left(A_{s, i} / P_{o, i}\right)+18,33 \square\left[\left(1-J_{\sigma s, i}\right)^{1 / 2}-0,5\right]\right\},
$$

where $A_{s, i}$ is the cross-sectional area of a composite steel element of a welded I-beam, $\mathrm{cm}^{2}$; $P_{o, i}$ is the perimeter of heating of the compund element cross-section, sm; $J_{\sigma s, i}$ is the intensity of strength stress in the cross section of a compound element $(0.1-1.0)$.

The indicator of heating conditions of the checkpoint of a welded I-beam shelf with fire-proof coating in conditions of fire testing (when $a_{x} \leq a_{y}$ ) is calculate by exponential function

$$
m_{o}=0,5 \cdot\left(a_{y} / a_{x}\right)^{0,5},
$$

where $a_{y}$ is thickness of fire-proof coating of a welded I-beam shelf along its Y-axis, $\mathrm{mm}$; $a_{x}$ is he depth of coverage according to the direction of checkpoint shift for finding the average temperature of the unevenly heated section of the shelf of a welded I-beam, which is calculated by using the power function 


$$
a_{x}=\delta_{x}+\left(\delta_{x} \square b / 2\right)^{n},
$$

where $\delta_{x}$ is thickness of fire-proof coating of a welded I-beam shelf along its horizontal axis, $m m ; n$ is the exponent calculated by using the power function

$$
n=0,5 \cdot(b / H)^{0,25} \text {, }
$$

where $b$ and $H$ are the flange width of an I-beam and the height of a cross-section of a welded steel fire-protected corrugated beam, $\mathrm{mm}[7,8]$.

Degree of fire protection of a compound element of a welded I-beam $C, \mathrm{~cm}$, is found out by using the analytical expressions

$$
C=1,45 \cdot m_{o i} \cdot \delta_{o, \min } / D_{b m}{ }^{0,8},
$$

where $m_{o i}$ is an indicator of heating conditions of the checkpoint of a welded I-beam $(0.5 \div$ $1.0) ; \delta_{o, \min }$ is the minimum thickness of the protective coating along one of the coordinate axes, $\mathrm{mm} ; D_{b m}$ is an idicator of thermal diffusion of the coating material , $\mathrm{mm}^{2} / \mathrm{min}[14,15]$.

Fire resistance duration effects $f_{u r, i}$, $\min$ of the corrugated web, as well as lower and upper shelves of a welded I-beam with account of fire protection, is calculated by an analytical equation

$$
f_{u r, i}=48 \square\left(1-J_{\sigma s, i}\right)^{3} \sqsubset e^{C}+r_{u s, i},
$$

where $J_{\sigma s, i}$ - is the intensity of the power voltage in the metal compound of the welded Ibeam $(0.1-1.0)$; $C$ is the degree of fire protection of a compound element of the welded Ibeam, $\mathrm{cm} ; r_{u s, i}-$ is duration of resistance of a compound element of the welded I-beam without taking into account its fire protection, $\min ; e=2.718$ is a natural number.

The design limit of fire resistance $F_{u r}$, min of a steel fire-proof corrugated beam of a building according to the loss of its bearing ability, can be identified by using the condition

$$
F_{u r}=f_{u r, \text { min }}
$$

where $f_{u r, \text { min }}$ - is fire resistance duration of compound elements of a welded I-beam, the least stable element (according to its statical and heat-resistant characteristics), $\mathrm{min}$.

The scheme of sections of steel corrugated fire-proof beams protection in conditions of fire are determined, depending on the actual location of the parts of the building $[9,10,11]$.

The scheme of a steel corrugated beam is shown on Figure 1. section $A-A-a$ longitudinal section; section $\mathrm{B}-\mathrm{B}-\mathrm{a}$ cross section; section $\mathrm{C}-\mathrm{C}-\mathrm{a}$ corrugated beam scheme. 1 - lower shelf; 2 - upper shelf; 3 - corrugated web; h and b-the height and width of a welded I-beam, $\mathrm{mm}$; $\mathrm{d}$ and $\delta_{\mathrm{s}}$ - are the thickness of the corrugated web and thickness of shelves, $\mathrm{mm}$.

The main single indicators of quality that provide fire resistance of steel fire-proof corrugated beams include: thermal diffusion rate and density of the fire-proof material, indicator of heating conditions of a compound element of a welded I-beam, thickness of protective coating, steel grade, the limit of its strength, critical temperature, thickness of a metal part of a compound element of a welded I-beam, the intensity of the stress in the cross section of a compound element of a welded I-beam; time resistance of a compound element of a welded I-beam without fire protection. [12-14].

A section of a welded I-beam of a steelcorrugated beam, fitted with frame elements of thermo-protective zones of the shelves with quadrihedral heating of beams sections in conditions of fire, is shown on Figure 2. 

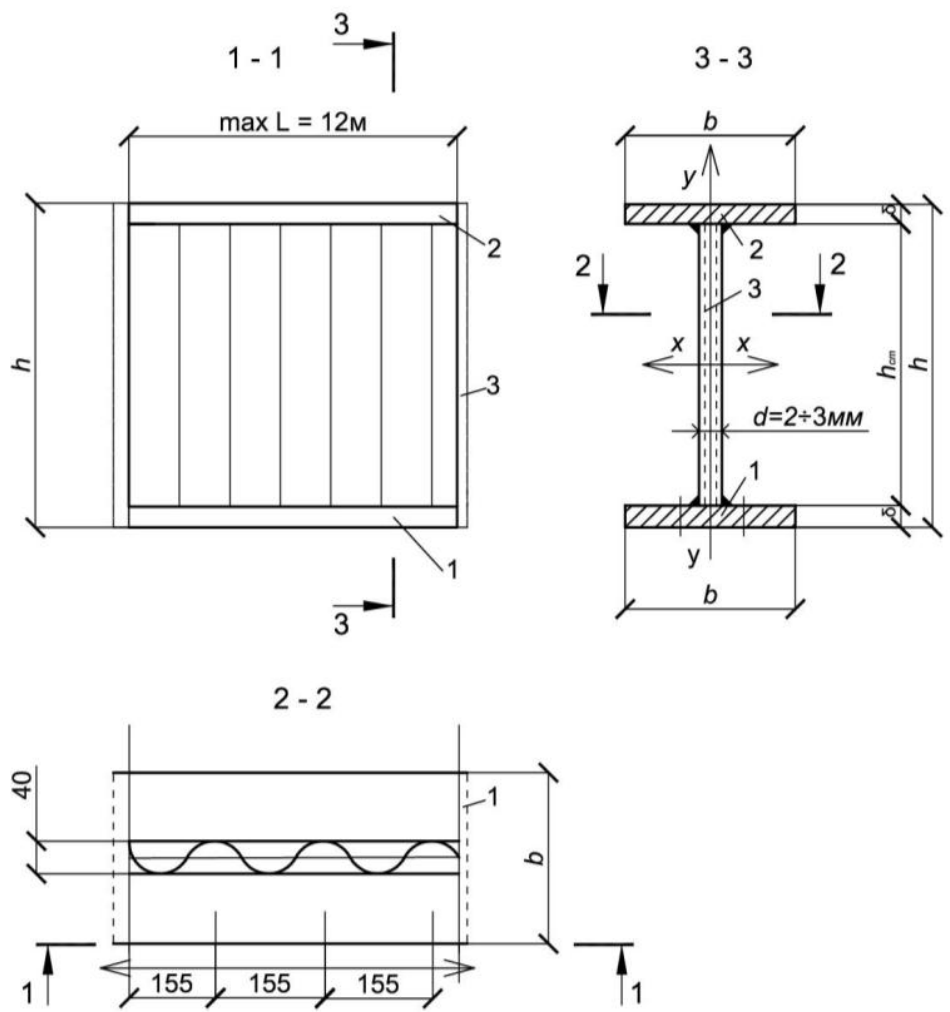

Fig. 1. The scheme of a steel corrugated beam

Figure 3 shows the section of a corrugated beam with thermo-protection zones filled with quadrihedral heating of the section in conditions of fire. 1 - lower shelf; 2 - upper shelf; 3 - corrugated web; 4 - U-section welded to the lower shelf; 5 - U-section welded to the upper shelf; 6 - weld; 7 - anti-corrosive coating; 8 - thermo-protective slab; 9 gypsum board; 10 - covering material (along the grid); 11 - checkpoint of shelves; 12 checkpoint of the corrugated web; $\mathrm{t}_{\mathrm{cm}},{ }^{\circ} \mathrm{C}$ - high temperature direction. A section of a welded I-beam, fitted with frame elements of fire-protective zones with triangle heating of beams sections in conditions of fire, is shown on Figure 4.

Figure 5 shows the section of a corrugated beam with fire-protection zones filled with triangular heating of the section in conditions of fire.

Action sequence in evaluating fire resistance of a steel fire-proof corrugated beam of a building is as follows. First, a suite of simple metrics of the quality of each element (corrugated web, the lower and upper shelves), influencing fire resistance, should be appointed. Then, conditions of ends fastening and dangerous cross-section elements of a welded I-beam should be identified. At last, single indicators of steel fire-proof corrugated beam quality and their integral parameters are estimated and, finally, the design limit of fire resistance of a tested corrugated beam is determined.

Under visual inspection we understand checking of the condition of the steel fire-proof corrugated beam, including identification of fixing conditions, heating of compound elements of a welded I-beam conditions, identification material for constructive protection of steel corrugated beams from heating in conditions a fire (concrete, plasterboard, gypsum blocks, vermiculite plates, mineral wool, plaster, etc.), the shape of the cross-section of the compound element of a welded I-beam, their geometric dimensions, steel grade, test load. 


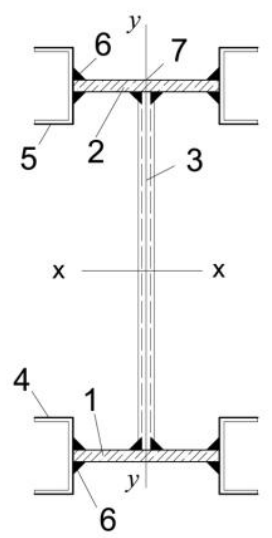

Fig. 2. A section of a welded I-beam of a steel corrugated beam, fitted with frame elements of thermo-protective zones of the shelves with quadrihedral heating of beams sections

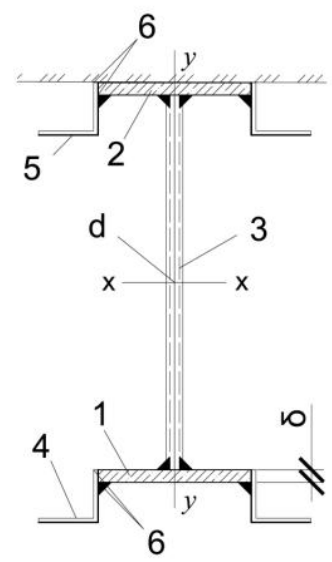

Fig. 4. A section of a welded I-beam, fitted with frame elements of fire-protective zones with triangle heating of beams sections

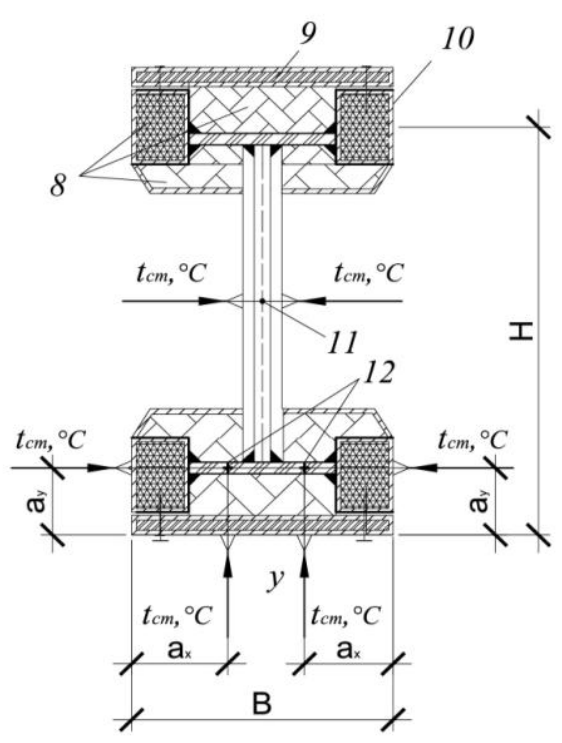

Fig. 3. The section of a corrugated beam with thermo-protection zones filled with quadrihedral heating of the section



Fig. 5. The section of a corrugated beam with fire-protection zones filled with triangular heating of the section

To verified geometrical parameters, we refer: thickness of protective coating, the width and height of cross-section of compound element of a welded I-beam of a steel corrugated 
beam. Dangerous sections of a steel corrugated beam elements are assigned in places of the greatest moments and shear forces from the test load. Dimensions of steel structure elements are checked with an accuracy of $\pm 1 \mathrm{~mm}$. [10;11].

The proposed method has been applied when evaluating fire resistance of fire-proof steel corrugated beams by LLC "Firma Meta-Com" (Samara).

\section{Conclusions}

The designed technological solution on fireproofing steel structures is referred to the sphere of fire safety of buildings and structures, and can be used for classification of corrugated beams according to indicators of their resistance to high temperature exposure of a standard fire.

A new resource-saving system of actions aimed to provide constructive fire protection of steel corrugated beams of buildings with elevated technical and economic indicators and the required fire resistance was obtained.

The technological effect is achieved by conducting firing tests of steel construction by non-destructive methods; evaluation of fire resistance of fire-protected elements of a corrugated beam (corrugated web, upper and lower shelves), by identifying the least stable element (according to its static and heat-resistant characteristics) of a welded I-beam at the minimum duration of fire resistance effects of corrugated webs; the design limit of fire resistance of steel corrugated beam is identified according to the duration of resistance to high temperature exposure of the least weak element of a welded I-beam $[15,16]$.

In the suggested methodology fire resistance duration of the constituent elements of a welded I-beam with account of its fire protection ability is described with an analytic function taken as variables. These variables are intensity strength of stresses and the degree of fire protection of a compound element (10).

\section{References}

1. N.A. Ilyin, S.S. Vedernikov. Patent №. 2320982 RU, MPK G 01 N 25/50

2. N.A. Ilyin, D.A. Panfilov, E.V. Ildiyarov, A.O. Lukin, A way of assessing fire resistance of steel thermo-protected, SIN beam of building structures. (to be published)

3. P.Wang et al., Thin-Walled Structures 98, 29-38 (2016)

4. V.K.R. Kodur et al. Journal of Constructional Steel Research 97, 48-58 (2014)

5. N.A. Ilyin, A.P. Shepelev, P.N. Slavkin, R.R. Ibatulin. Patent No. 2522110 (2006.1) MPK E 04 in 1/94,

6. N.A. Ilyin. Fire protection design of buildings and structures (Textbook, Moscow, 2013)

7. P.Wang et al. Journal of Constructional Steel Research 126, 92-106 (2016)

8. N.A. Ilyin, A.S. Kowalewski, E.Yu. Pakhomov, A.V. Cherepanov. Patent No. 2282 847. statements.

9. A.P. Pilyugin, Ensuring explosion stability of buildings by using safety structures (2003)

10. I.L. Masalkov, G.F. Plusina, A.Yu. Frolov, Fire resistance of building structures (2001)

11. P. et al. Thin-Walled Structures 98, 58-74 (2016)

12. N.A. Ilyin, S.S. Vedernikov. Patent No. 2320982. 
13. N.A. Ilyin, S.S. Vedernikov. A method of parameter estimation of fire in a building (Patent No. 2381 491. req. SGASU 20.10.2008; pub. 10.02.2010, Bul. № 4.)

14. N.A. Ilyin, V.V. Frygin, A.P. Shepelev. A method of making a sample for testing of fire-proof coatings (Patent No. 2451 925. req. SGASU 30.06.2010; pub. 27.05.2012, Bul. № 1.)

15. N.A. Ilyin, D.A. Panfilov, D.V. Litvinov, P.N. Slavkin, Urban Construction and Architecture 1, 82-89 (2015). DOI: 10.17673/Vestnik.2015.01.13

16. N.A. Ilyin, D.A. Panfilov, D.V. Litvinov, N.V. Tretyakov, Urban Construction and Architecture 3, 112-119 (2015). DOI: 10.17673/Vestnik.2015.03.15 